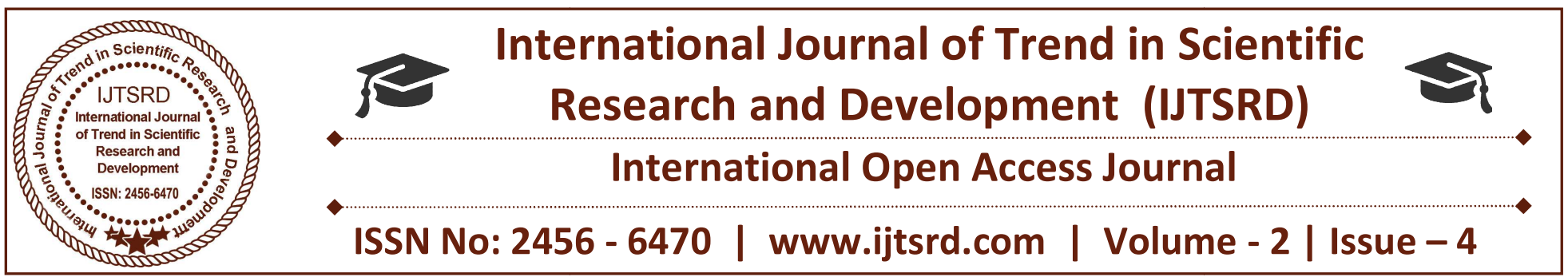

\title{
Train Tracker using GPS System
}

\author{
Rupali Chaughule \\ MCA, Bharati Vidyapeeth's Institute of Management and Information Technology, \\ Navi Mumbai, Maharashtra, India
}

\begin{abstract}
Now a days, Travelling from train is a important part of the each and every person and it is fastest way to travel in the city. But, as the need of the train is increases the train accidents and violation is also increasing day by day. This research paper presents a solution for passengers to track running train status. This can be possible by GSM and GPS. Train tracker provides the comfort to passengers and helps to catch their trains and also check that where train is currently running.
\end{abstract}

An Indian train passenger daily faces the train delay problem and it impacts on their work. In this runway life people need to know that where train is located which they are going to catch. It will saves the time and also provide the comfort.

This paper I present to improve the existing train system. To improve this train system it uses the powerful software like GPS which helps to find the current position of the object. Here object is a train and continuous moving of the train will be indicating on the mobile device of the passengers.

Keywords: Train locator, Train tracker, train control, GPS,

\section{INTRODUCTION}

There are many safety and security issues in India which results the daily accidents and injury. To avoid these big issues train locator provide it's best contribution to help people and SCR (South Central Railway ) is currently using the train-tracking system and provides train location.

The train tracker uses the GSM, GPS and Google map to track the current location of the train. The signals receive from the satellite and location of the train is track in Google map. Government is always trying to improve the train services. The passengers always suffer with the train delay problem and they have to wait for long time. Train tracking system using GPS provide the solution for this problem.

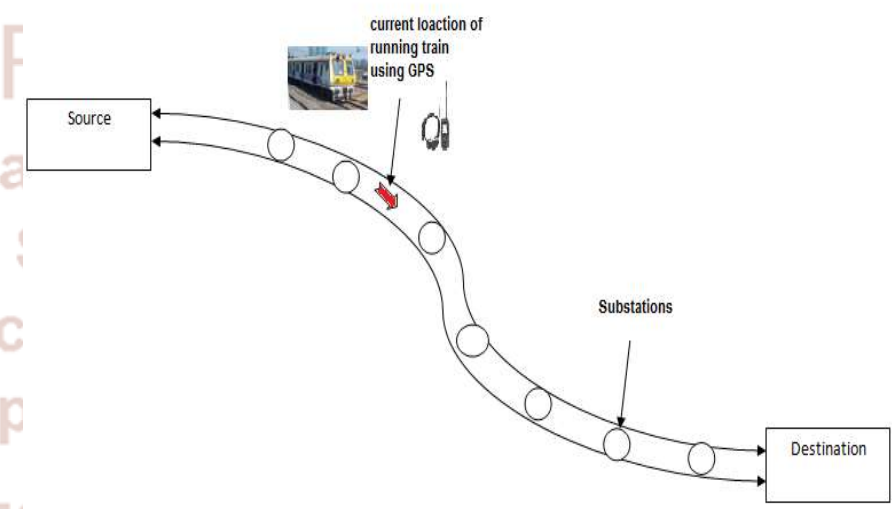

\section{Present Working Scenario of Train:}

Now a days, passengers checks the trains time online or the timetable of the trains is already available at the stations. But sometimes, because of accidents, technical problems, and other issues, passengers always faces train delay problem or train cancellation problem. In this scenario, people don't get the idea of train arrival time.

Indian Railways are one of the biggest transportation networks in the world providing lakhs of job. Being biggest sector there are some key problems which are to be rectified in order to ensure the complete safety of passengers. Such problems are flaws in tracks and collisions of trains.

Whenever a particular train arrives at a station, the 
information should be sent to that specific station control room \& to headquarters.

Usually Station master will pass this information to the control room through landline communication .i.e. information is passed manually. The control of the train is under the station Master. But this manual operation strictly depends on keen observation of station master \& the proper communication through landline. Otherwise train collisions and accidents may happen. In addition if a train was stuck at any of the stations in a section, this information cannot be obtained immediately.

With the growing of high speed railway traffic and to reduce practical human errors, there is a need to develop an automatic train tracking system. This enables to identify the exact location of trains at any time. This system automatically passes the information to the station control room. The information to the headquarters is passed through rail net. This application will surely help in creation of efficient, punctual and safe transportation service. This is also useful to avoid land line communication errors.

\section{Difficulties in Present Process}

The provision of safe and reliable services is a fundamental requirement of the railway as thousands rely on this service as their prime mode of transportation. The Railway department of India carries about millions of passengers per annum and the safety of such service can never be taken. Passengers are entitled to expect to travel in safety throughout their journey and the government should be committed to protect the passengers and employers form any safety issue that might rise during journey. Effective safety planning requires a detailed understanding of key risk areas; this allows resources and effort to be concentrated where they will have greatest impact.

The main safety issues are in the form of accidents that mostly involve third parties other than the passengers and the employers. Most of the infrastructure issues are associated with signalling and accident. This can be addressed by developing a communication channel between the train and control centre. The control centre should be able to identify the train's location to recognize possible safety threats; such as collisions. The control centres should also be able to notify the locomotive drivers of the security threat. This will allow the drivers to avoid or at least minimize the harmful issues. New systemmanagement technology combined with accurate knowledge of train position will give the opportunity to present drivers aimed at maintaining the flow of traffic by regulating trains to await paths. Human intervention at control centres can lead to accidents due to human error or negligence.

This problem can only be solved via an automated system, which will handle these tasks and would consequently avoid human errors.

\section{GPS System use:}

Rail systems throughout the world use GPS to track the movement of rail. When combined with other sensors, computers, and communications systems, GPS improves rail safety, security, and operational effectiveness. The technology helps reduce accidents, delays, and operating costs, while increasing track capacity, customer satisfaction, and cost effectiveness. U.S. passenger and freight railroads are fielding GPSbased Positive Train Control (PTC) systems. PTC refers to communication-based/processor-based train control technology designed to prevent train-to-train collisions, over speed derailments, incursions into established work zone limits, and the movement of a train through a main line switch in the improper position.

GPS is used to synchronize the timing of railroad communication systems, including data transmissions for PTC, voice contact between locomotive engineers and dispatchers, and intermodal communications among trains, rail stations, ports, and airports.

\section{Working of Tracking system using GSM, GPS, ARM7:}

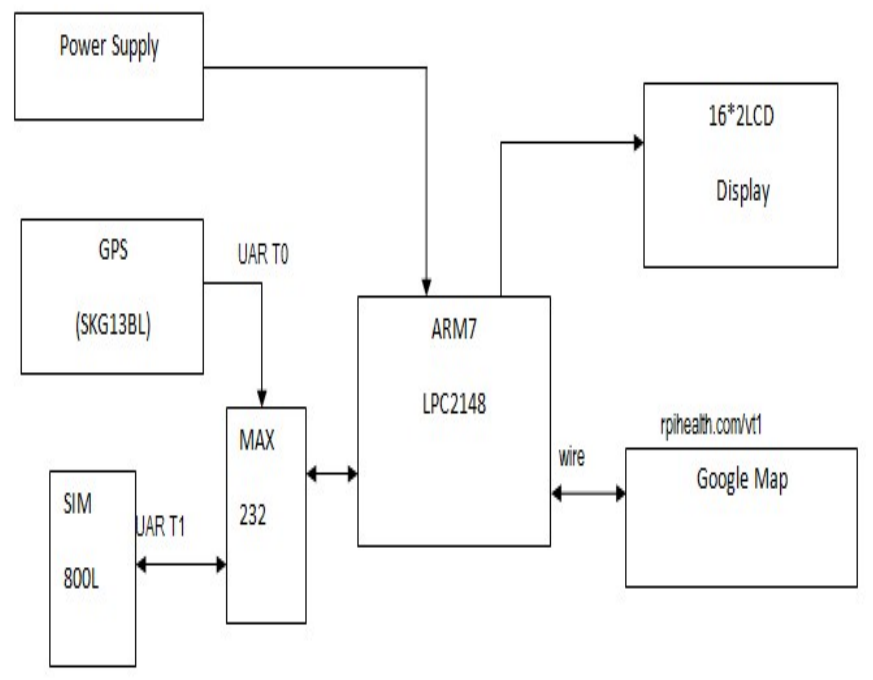


Using Arm7 LPC $2148 \quad 32$ bit processor, GPS(SKG13BL), SIM 800L

Arm7 is connected to the MAX232 and MAX32 is connected to GPS(SKG13BL) with UAR T0 and it also connected with the SIM 800L with UAR T1. $16 * 2 \mathrm{LCD}$ Display is used to display continuous process of processor. Next using rpihealth.com/vt1 on Google map. It shows the latitude and longitude values with present date and time.

\section{Hardware part}

I used 230 input step down transformer $0-12$ wholes with transformer connected with Bridger rectifier. It also contain on/off switch. When switch is on the entire kit should be on. All components are utilizing 5 maximum power supply. When all above connection setup is done status LED is continuously blinks then connect power supply to the GPRS module. Whenever we got signal from cell phone tower then we can go for the GPRS, without signal it is not possible. Data is send to the server in every 30 seconds and it will send alert to the mobile phone. When we open the message url in phone browser, it will show the location in the Google map and every 30 second page will be restarted. This is how when train is moving it continuously track the data from satellite and data will send to the phone. It is very useful for the passengers. It can also used to track the vehicles.

GPS satellite simply broadcast the signals.

\section{Benefits}

$>$ Increased situational awareness for improved safety of trains and maintenance crews.

$>$ Prevention of collisions, derailments, work zone incursions, and rail switch errors.

$>$ Increased capacity and efficiency for all rail users. Automated track surveys and inspections.

$>$ Time synchronization for communication systems.

$>$ Easy to locate the train on the mobile device

$>$ Saves the lots of time

$>$ Prevents the train accidents

$>$ Provide peaceful travelling to the passengers

$>$ Improves the transportation of local trains

\section{FUTURE SCOPE}

Addressing this work showed us that there exist the potential to build support systems for automatic train driving. In order to continue in the pursuit of this objective multiple strategies can be followed to improve the system. Here we list some of them.
Correct identification of the objects is an important step for the system. In this work we used the infrared sensor for obstacle detection. However, when the railroad is curved the method is quite inaccurate in the remote areas of the rails. To compensate for this it is necessary to evaluate alternative strategies to capture more accurately the inclinations of the rails and find a more appropriate objective according to the actual scene. A candidate method is the use of ultrasonic sensor or IJSER International Journal of Scientific \& Engineering Research, Volume 4, Issue 8, August2013292 ISSN 2229-5518 IJSER (C) 2013 http://www.ijser.org radar that can much better fit to the rail. Learning and identification of benign object provides interesting challenges for computer vision algorithms. Further enhancements of such system would even grant passengers capabilities such as text messages informing accurate arrival and departure times and even the seating capacity of the train. . Location data can be further processed to provide visual positioning using maps granting a wholesome view on train location. Additionally, the location information can be used to facilitate accurate scheduling with regard to train arrival and departure on each station..It is completely integrated so that once it is implemented in all trains, then it is possible to track from anywhere at any time.

\section{REFERENCES:}

1. Zehang Sun, George Bebis, and Ronald Miller, "On Road Train Detection: A Review " IEEE Transactions On Pattern Analysis And Machine Intelligence, Vol. 28, No. 5, May 2006

2. J. Xue, J. Cheng, L. Wang, X. R. Gao, "Visual Monitoring-based Railway Grade Crossing Surveillance System", CISP

3. https://economictimes.indiatimes.com/industry/tra nsportation/railways/indian-railways-to-launchreal-time-train-tracking-via-googlemaps/articleshow/12421606.cms

4. https://railradar.railyatri.in/

5. http://www.indianrailway.gov.in

6. https://www.railyatri.in/live-train-status

7. https://www.gps.gov/applications/rail/

8. https://timesofindia.indiatimes.com/travel/destinat ions/real-time-train-tracking-is-possible-now-dueto-special-gps-enabled-system/as61864519.cms

9. https://ieeexplore.ieee.org/document/6659409/

10. https://www.vr.fi/cs/vr/en/live-train-mapinformation 